\title{
A Rede de Atenção Psicossocial sob o olhar da complexidade: quem cuida da saúde mental?
}

\author{
The Psychosocial Care Network under the look of complexity: who \\ cares for mental health?
}

Déborah Karollyne Ribeiro Ramos Lima', Jacileide Guimarães ${ }^{\mathbf{1}}$

DOI: 10.1590/0103-1104201912218

RESUMO Objetivou-se pensar a Rede de Atenção Psicossocial, suas tensões e contradições, através das lentes compreensivas do pensamento complexo. Trata-se de ensaio teórico e analítico, apresentado na forma de exposição lógico-reflexiva, com ênfase na argumentação e na interpretação pessoal. Para embasamento teórico-conceitual, realizou-se revisão narrativa da literatura pelo cruzamento de palavras-chave em várias bases de dados eletrônicos. Vê-se o serviço especializado como o cenário privilegiado da atenção. As relações em rede são ainda incipientes e carecem de uma maior aproximação à matriz conceitual das Redes de Atenção à Saúde. Julga-se primordial garantir a integração e a interlocução dos pontos de atenção das redes de saúde no território. Por fim, aceitar a relação dialógica que se estabelece entre os espaços dentro/fora dos serviços, assim como a hologramaticidade que se estabelece entre a Rede de Atenção Psicossocial/Redes de Atenção à Saúde e apostar na interdisciplinaridade e na intersetorialidade parece uma alternativa para fazer fluir o cuidado e as relações em rede.

PALAVRAS-CHAVE Saúde mental. Serviços de saúde mental. Atenção à saúde.

1 Universidade Federal do Rio Grande do Norte (UFRN) - Rio Grande do Norte (RN), Brasil. deborah.ribeiro.ramos@ gmail.com

\begin{abstract}
The objective was to think the Psychosocial Care Network, its tensions and contradictions, through the comprehensive lenses of complex thought. This is a theoretical and analytical essay, presented in the form of a logical-reflexive exposition, with emphasis on argumentation and personal interpretation. For a theoretical-conceptual basis, a narrative review of the literature was carried out by crossing keywords in several electronic databases. The specialized service is seen as the privileged setting for care. Networked relationships are still incipient and require a closer approximation to the conceptual matrix of Health Care Networks. It is judged essential to guarantee the integration and interlocution of health work points of care in the territory. Finally, accept the dialogical relationship established between the spaces inside and outside the services, as well as the hologramaticity that is established between the Psychosocial Care Network/Health Care Networks and to bet on the interdisciplinarity and the intersectoriality seems like an alternative to make the caring and the networked relationships flow.
\end{abstract}

KEYWORDS Mental health. Mental health services. Health care (public health). 


\section{Introdução}

A Reforma Psiquiátrica Brasileira (RPB) apresenta-se como o grande marco da reorientação teórico-prática da loucura no Brasil. Nascida no interior do processo de conscientização sanitária, vem, desde os primeiros anos do movimento de Luta Antimanicomial até os dias atuais, promovendo incontestáveis avanços em todo território nacional e nos diversos âmbitos que conformam suas múltiplas facetas - teórico-conceitual, jurídico-político, técnico-assistencial e sociocultural'.

A partir do ano de 2011, após a Portaria Ministerial n ${ }^{\circ} 3.088 / 2011^{2}$, os serviços de saúde mental passaram a se organizar seguindo a lógica das Redes de Atenção à Saúde (RAS) - sistema integrado que opera de forma contínua, proativa e voltado para as condições agudas e crônicas de saúde/doença ${ }^{3}$-, estabelecendo, assim, a rede temática, e prioritária, de cuidados em saúde mental: Rede de Atenção Psicossocial (Raps).

É fato que, desde a sua institucionalização, a Raps vem passando por avanços e retrocessos. Alguns dos desafios que se impõem à referida rede temática podem ser assim enunciados: atenção à crise, principalmente pela escassez de dispositivos substitutivos que atendam 24 horas por dia; aproximação entre Atenção Básica (AB) e os Centros de Atenção Psicossocial (Caps); formação de laços entre os indivíduos e entre estes e a cidade; inclusão dos setores de educação, justiça, assistência social, direitos humanos na luta pela cidadania; continuidade do cuidado em território; e a postura centralizadora que vem sendo assumida pelo Caps (ou imputada a este pelos outros elementos da Raps) como organizador da atenção em nível territorial ${ }^{4}$ quando, em tese, tem-se a Atenção Primária à Saúde (APS) como ordenadora da rede e coordenadora do cuidado.

Neste ensaio, aprofundaremos as discussões sobre o emaranhado de tensões e contradições que afloram no cotidiano de serviços, atores e setores que compreendem a Raps - novo desenho organizativo que se propõe a oferecer assistência integral, contínua e de base comunitária ao usuário em sofrimento psíquico. Neste artesanato intelectual, iremos trilhar a interface saúde mental/saúde coletiva para que assim possamos compreender a lógica que orienta a organização e estruturação dos serviços de saúde mental substitutivos ao hospital psiquiátrico. Lançando um ‘olhar-caleidoscópio'5 sobre a Raps, almejamos pensar a rede viva, em movimento, reconhecendo a sinergia que se estabelece entre esta e as RAS.

Para lançar esse olhar ampliado sobre a Raps subsidiar-nos-emos de conceitos fundamentais do pensamento complexo. Recorremos ao auxílio das lentes compreensivas da complexidade por sua capacidade de reconhecer a interconexão entre as múltiplas dimensões da realidade e a inter-relação entre cada ser vivo, ambicionando refletir sobre as articulações que foram/são destruídas pelos cortes entre disciplinas, entre categorias cognitivas e entre tipos de conhecimento $^{6}$. Tal característica parece-nos interessante em face da própria ideia de atenção em redes de saúde e ao apelo de integralidade que emana das entrelinhas das Portarias Ministeriais $\mathrm{n}^{0} 4.279 / 2010^{7}$ e n $^{0} 3.088 / 2011^{2}$.

Diante do exposto, o presente ensaio tem como objetivo pensar a Raps, suas tensões e contradições, através das lentes compreensivas do pensamento complexo.

Ressaltamos a importância de pensar/problematizar a Raps inicialmente pela posição que esta ocupa na lista de programas prioritários do Ministério da Saúde. Além disso, urge a necessidade de fortalecer o discurso e a concepção da rede de saúde mental a partir da lógica das RAS, sobretudo em face da alteração que vem sofrendo a Política Nacional de Saúde Mental por meio da Resolução $n^{0} 32^{8}$ e da Portaria ${ }^{\circ} 3.588^{9}$, ambas de dezembro de 2017.

\section{Métodos}

Trata-se de ensaio teórico e analítico, apresentado na forma de exposição lógico-reflexiva, com ênfase na argumentação e na interpretação pessoal. 
Para discussão e problematização do fenômeno em foco, realizamos revisão da literatura da área que contou com busca nas bases eletrônicas de dados da Biblioteca Virtual em Saúde, do Portal de Periódicos da Coordenação de Aperfeiçoamento de Pessoal de Nível Superior (Capes), do Banco de Teses da Capes e da Biblioteca Digital Brasileira de Teses e Dissertações. Foram utilizados o descritor 'saúde mental' articulado à palavra-chave 'Rede de Atenção Psicossocial' pelo operador booleano AND. Foram selecionados 21 trabalhos, dos quais eram 12 artigos e 9 dissertações. O cruzamento foi realizado em março de 2017, contando também com busca ativa em livros e materiais impressos que se estendeu por todo ano de 2017. Com o intuito de atingir o maior alcance possível de obras que contemplassem direta ou indiretamente o problema em análise, não se delimitou marcador temporal ou idioma, sendo a busca orientada por proximidade teórica/temática.

O produto desta busca foi submetido à leitura e análise crítica das autoras e, na sequência, dividido em duas seções: 1) Considerações sobre o pensamento complexo; 2) Refletindo sobre a Raps a partir do olhar da complexidade.

\section{Considerações sobre o pensamento complexo}

O pensamento complexo, também referenciado como complexidade, Teoria da Complexidade ou paradigma complexo, vem sendo desenvolvido, na tradição moriniana, desde a década de 1960. Edgar Morin traça seu caminho a partir da teoria da informação, da cibernética, da teoria dos sistemas, do conceito de auto-organização e da microfísica, mais especificamente do conceito de sistema aberto no qual sujeito e objeto mantêm relação (sujeito/ ambiente; sistema/ecossistema). O reconhecimento das relações sujeito/objeto representa um dos precedentes que se abre para a virada paradigmática que propõe a integração das realidades banidas pela ciência clássica ${ }^{10}$.
Nesse sentido, a complexidade é entendida como:

o tecido de acontecimentos, ações, interações, retroações, determinações, acasos que constituem nosso mundo fenomênico, [...] se apresenta com os traços inquietantes do emaranhado, do inextricável, da desordem, da ambiguidade, da incerteza10(13).

De tal modo, a Teoria da Complexidade ambiciona exercer um pensamento capaz de lidar com o real e com ele dialogar e negociar, privilegiando as

articulações entre os campos disciplinares que são desmembrados pelo pensamento disjuntivo, que isola o que separa e oculta tudo que religa, interage, interfere ${ }^{\mathbf{1 0}(13)}$.

Justificamos nossa opção teórico-conceitual inicialmente por ser uma abordagem que se contrapõe ao reducionismo e ao determinismo positivista hegemônico, possibilitando que lancemos um olhar ampliado sobre a Raps, que é essencialmente complexa. Por outro lado, consideramos que os seres humanos e a própria sociedade - e por que não dizer os sistemas de saúde? - estão em constante construção-desconstrução-reconstrução, por isso a necessidade de lidar com o inesperado e com as certezas provisórias.

Assim, admitimos a possibilidade do diálogo entre o pensamento complexo e os fenômenos envolvidos na busca da integralidade das RAS, e, por extensão, da Raps ${ }^{\mathbf{1 2}}$; inspirados em Amarante ${ }^{11(18)}$ ao referir que a própria

[...] natureza do campo da saúde mental vem contribuindo para que comecemos a pensar de forma diferente, não mais com este paradigma da verdade única e definitiva, mas sim em termos de complexidade, de simultaneidade, de transversalidade dos saberes,

Para iluminarmos pontos cegos, nos movimentando no terreno das inter-relações e 
interconexões ${ }^{\mathbf{1 3}}$, valer-nos-emos, neste ensaio, de princípios e conceitos fundamentais do pensamento complexo. Dialógica, recursividade organizacional, holograma, além do tetragrama da complexidade conformado pela 'fórmula paradigmática' ordem-desordem-interação-organização são os conceitos-chave que nos acompanharão nesta análise.

O princípio dialógico nos auxilia a entender os fenômenos como simultaneamente antagônicos, concorrentes e complementares; permite-nos manter a dualidade no seio da unidade e, assim, conceber a existência da ordem em meio à desordem. A recursão organizacional, ou recursividade, indica a compreensão de que efeitos de um processo são também seus coprodutores; é uma ruptura com a ideia linear de causa/ efeito, de produto/produtor, já que tudo que é produzido volta-se em um ciclo autoconstitutivo, auto-organizador e autoprodutor. O holograma, por sua vez, refere-se à ideia de que a parte está no todo, assim como o todo está na parte, de modo que as partes não dão conta de explicar o funcionamento do todo. Assim, estimulam a utilização de procedimentos científicos mais dinâmicos, interativos, recursivos e não lineares $\mathbf{1 0 , 1 4}^{\mathbf{1 4}}$.

O tetragrama da complexidade propõe a dialogicidade entre os termos ordem-desordem-interação-organização como uma fórmula paradigmática para conceber o jogo de formações e transformações sem esquecer a complexidade do universo. Dentro dessa perspectiva, compreende-se a ordem como ideia de determinação, estabilidade, constância, regularidade, repetição; já a desordem é vista como acaso, agitações, dispersões, colisões, irregularidades e instabilidades, desvios no processo, choques, encontros aleatórios, acontecimentos, ruídos e erros. Atualmente, a ideia de ordem está ligada à ideia de interação, de modo que ordem e desordem, mesmo parecendo 'inimigas', se espiadas por olhos desatentos, cooperam de certa maneira para organizar o universo ${ }^{15}$. Nessa lógica, são como duas facetas de uma mesma moeda.
Familiarizados com os conceitos-chave do pensamento complexo, sigamos à discussão da Raps.

\section{Reflexões sobre a Rede de Atenção Psicossocial a partir do olhar da complexidade}

Para iniciar esta discussão julgamos pertinente resgatar o cenário de transformações ideológicas e jurídico-políticas que prepararam o terreno para o estabelecimento das RAS como uma estratégia potente no contexto sociossanitário brasileiro. Manobra que supomos necessária diante da hologramaticidade que se reconhece entre RAS/Raps e que, em analogia ao pensamento de Edgar Morin ${ }^{10}$, autoriza-nos a reconhecer que a Raps está na RAS, que por sua vez está na Raps.

Imaginemos, então, um cenário marcado pela ampliação do conceito de saúde no qual o processo saúde-doença passa a ser reconhecido como produto e produtor de uma complexa rede de produção social. Tal redirecionamento fez avançar, no Brasil, o entendimento da saúde como resultante de complexas redes multidimensionais que envolvem elementos biológicos, subjetivos, sociais, econômicos, ambientais e culturais, atuando de maneira simultânea e inseparável na experiência concreta de sujeitos e coletividades ${ }^{\mathbf{1 6}}$. Por outro lado, reconheçamos que a reformulação da Constituição Federal em 1988 e a criação do Sistema Único de Saúde (SUS), ao definir a saúde como direito de qualquer cidadão e dever do Estado, fomentaram transformações no setor saúde balizadas pelos ideais de universalização e democratização do acesso aos serviços, equidade e integralidade da assistência.

Com a nova sensibilidade do conceito ampliado de saúde na percepção dos processos saúde-doença e dos contextos a eles vinculados, emerge a necessidade de inovações que permitam a criação de múltiplas respostas no 
enfrentamento da produção saúde-doença. Nessa perspectiva, as RAS surgem como uma alternativa para recompor a coerência entre uma situação de saúde marcada pela tripla carga de doenças - que envolve uma agenda não concluída de infecções, desnutrição e problemas de saúde reprodutiva, doenças crônicas e crescimento da morbimortalidade por causas externas - e o sistema de atenção à saúde, objetivando, assim, transpor a assistência fragmentada, episódica, reativa e focada nas condições e eventos agudos e na agudização das condições crônicas ${ }^{\mathbf{1 7}, 18}$.

No âmbito da saúde mental, paralelamente, as mudanças nas formas de compreender o transtorno mental e de cuidar do indivíduo em sofrimento psíquico passam a exigir novas formas de estruturação e de organização dos serviços - assim como de itinerário dos usuários - em prol da desinstitucionalização da assistência em saúde mental, com ênfase no tratamento extra-hospitalar, da inclusão social da pessoa com transtorno mental ${ }^{19}$, da humanização da assistência, valorizando-se o protagonismo, a autonomia e a participação social dos sujeitos.

Foi no contexto de críticas ao modelo hospitalocêntrico de abordagem do transtorno mental e de politização da questão da saúde mental que foram produzidas reflexões que fomentaram movimentos de ruptura epistemológica, criação de experiências de cuidado contra-hegemônicas, mudanças em normas legais e efeitos socioculturais ${ }^{20}$. Em síntese, reconhecemos que o cenário efervescente de mudanças teórico-práticas e políticas que envolveu o setor saúde, de maneira geral, e o campo da saúde mental/atenção psicossocial, de modo específico, culminou mais recentemente com a reestruturação do sistema de saúde brasileiro de atenção à saúde mental segundo a lógica das RAS com a criação da Raps.

A Portaria Ministerial $n^{\circ} 4.279 / 2010$ conceitua a RAS como

[...] arranjos organizativos de ações e serviços de saúde, de diferentes densidades tecnológicas, que integradas por meio de sistemas de apoio técnico, logístico e de gestão, buscam garantir a integralidade do cuidado ${ }^{\mathbf{7}(4)}$.

Tem como característica a formação de relações horizontais entre os pontos de atenção, está centrada na necessidade de saúde da população, assumindo responsabilidade na atenção integral e contínua, além de oferecer um cuidado multiprofissional comprometido com os resultados sanitários e econômicos ${ }^{7}$.

A RAS apresenta-se como um conjunto de serviços de saúde organizados poliarquicamente e vinculados entre si por uma missão única, por objetivos comuns e por uma ação cooperativa e interdependente que busca aprofundar e estabelecer inter-relações entre os diversos nós que o compõe, o que implica e possibilita continuidade e integralidade da atenção ${ }^{3}$.

Em síntese, esse novo arranjo organizativo propõe a integralidade e continuidade do cuidado, a integração e interação de serviços e a construção de vínculos horizontais entre atores e setores em contraposição à fragmentação de programas e práticas clínicas, ações curativas isoladas em serviços e especialidades. Por esse motivo, a organização dos serviços em RAS é reconhecida como uma "estratégia para qualificar a atenção e a gestão do SUS"16(6).

São basicamente três os elementos constitutivos da RAS: população adscrita, estrutura operacional e modelos de atenção à saúde. A estrutura operacional da RAS, por sua vez, é composta por uma série de elementos que compreende o centro de comunicação focado na APS enquanto ordenadora da RAS e coordenadora do cuidado; pontos de atenção secundária e terciária; um sistema logístico conformado pelo cartão de identificação das pessoas usuárias, prontuário clínico eletrônico, sistema de acesso regulado à atenção e sistema de transporte em saúde; e sistemas de apoio diagnóstico e terapêutico, assistência farmacêutica e Sistemas de Informação em Saúde; além de um sistema de governança responsável pelo exercício da autoridade política, econômica e administrativa para gerir os negócios do Estado7. 
Devido à necessidade de enfrentamento de vulnerabilidades, agravos ou doenças específicas que acometem as pessoas ou as populações, foram organizadas cinco redes temáticas consideradas prioritárias no atual contexto sanitário brasileiro, sendo elas: a Rede Cegonha, a Rede de Atenção às Urgências e Emergências, a Rede de Atenção às Doenças Crônicas, a Rede de Cuidado à Pessoa com Deficiência e a Raps. Empenharemos nossas análises sobre esta última.

Diz-se rede temática, pois visa oferecer respaldo técnico-assistencial para o caminhar do usuário por uma linha de cuidado que toca uma necessidade específica desse indivíduo. A linha de cuidado é a imagem pensada para expressar o caminho a ser percorrido pelos sujeitos no sentido de atender às suas necessidades de saúde. Disparada pelos Projetos Terapêuticos Singulares, incorpora a ideia de integralidade da atenção, uma vez que contempla, entre as possibilidades terapêuticas, ações de prevenção, cura e reabilitação - integralidade vertical -, além de serviços inseridos no sistema de saúde e entidades comunitárias e da assistência social - integralidade horizontal. Tem no acolhimento, no vínculo e na responsabilização suas diretrizes ${ }^{\mathbf{2 1}}$.

No contexto da atenção em rede, destacam-se como verdadeiramente temáticos os pontos de atenção secundária e terciária, uma vez que aí estão alocados os serviços especializados e de alta complexidade. Entretanto, admitimos uma relação de complementaridade entre os serviços especializados e a APS na conformação das redes temáticas - a exemplo da Raps. Por isso, afirmamos que as redes temáticas complementam e são complementadas pelos demais componentes da RAS, incluindo-se os sistemas de apoio e logístico.

Essa relação de complementaridade entre as redes temáticas na conformação do todo da assistência em rede se dá pela superação da dicotomia entre os programas verticais e horizontais, rumo ao estabelecimento de
[...] programas diagonais, em que se combinam os objetivos singulares de determinadas condições de saúde com uma estrutura operacional que organiza transversalmente a APS, os sistemas logísticos, os sistemas de apoio e o sistema de governança22(26,27).

Uma das dificuldades é que, no atual contexto da atenção em rede, alguns temas (componentes temáticos) - a exemplo do transtorno mental e do uso abusivo de álcool e outras drogas -, por várias questões, vão ficando segregados. Barreiras vão sendo postas, transformando as curvas do território em labirintos que circunscrevem especialidades e especialistas. Igualmente difícil é reconhecer que, para fazer valer a integralidade da atenção, é preciso 'emaranhar' as linhas de cuidado, 'transdisciplinarizar', e, enfim, admitir a coexistência de múltiplas facetas nos processos saúde-doença de um usuário, que, em última instância, é um ser multidimensional.

Enquanto uma RAS temática, a Raps apresenta-se como um arranjo organizativo de ações e serviços de saúde de diversas complexidades assistenciais. Foi organizada a partir da necessidade de enfrentamento de vulnerabilidades relacionadas com os transtornos mentais e com o uso abusivo de crack, álcool e outras drogas. Em linhas gerais, objetiva ampliar e promover o acesso à atenção psicossocial da população e garantir a articulação e a integração dos pontos de atenção das redes de saúde no território, qualificando o cuidado por meio do acolhimento, do acompanhamento contínuo e da atenção às urgências ${ }^{2}$. Afirma-se que "a Raps é uma expressão da RPB para o fortalecimento do SUS como política de Estado"23(5), uma vez que possibilita e potencializa a integralidade do cuidado de base territorial ao indivíduo em sua existência-sofrimento.

A nova proposta organizacional para a saúde mental incorporou serviços, estratégias e ações para promover integralidade, continuidade e longitudinalidade do cuidado. De acordo com a Portaria $n^{0} 3.088 / 2011^{2}$ a Raps é constituída por sete componentes: 
- APS, na qual estão alocadas as Unidades Básicas de Saúde (UBS), os Núcleos de Apoio à Saúde da Família (Nasf), as Equipes de Consultórios na Rua e os Centros de Convivência e Cultura;

- Atenção psicossocial, que conta com os Caps em suas diversas modalidades - Caps I, Caps II, Caps III, Caps AD II, Caps AD III e Caps Infanto-juvenil - definidos por ordem crescente de porte/complexidade e abrangência populacional;

- Atenção de urgência e emergência por meio do Serviço de Atendimento Móvel de Urgência 192 (Samu), a Unidade de Pronto Atendimento (UPA) 24 horas, portas hospitalares de atenção à urgência/pronto-socorro e UBS;

- Atenção residencial de caráter transitório composta por unidade de acolhimento e pelos serviços de atenção em regime residencial, entre os quais estão as comunidades terapêuticas;

- Atenção hospitalar que é composta por leitos/enfermarias de saúde mental em hospital geral e pelo serviço hospitalar de referência para atenção às pessoas com sofrimento ou transtorno mental e com necessidades decorrentes do uso de crack, álcool e outras drogas;

- Estratégias de desinstitucionalização como os serviços residenciais terapêuticos e o Programa de Volta para Casa que consiste no auxílio reabilitação para pessoas com transtorno mental egressas de internação de longa permanência;

- Reabilitação psicossocial por meio de iniciativas de geração de trabalho e renda, empreendimentos solidários e cooperativas sociais.

Essa rede assistencial específica, da maneira como foi pensada e instituída no ano de 2011, reveste-se de fundamental importância por propor meios para a desconstrução do aparato manicomial e para a continuidade da assistência em território. Ainda que reconheçamos os avanços conquistados a partir da criação da Raps, não negamos as dificuldades vivenciadas por seus atores nos movimentos de tessitura da rede, seja pelos 'pés' do usuário que, ao circular por serviços e estratégias, desbrava caminhos e possibilidades de atenção, ou pela perspectiva dos trabalhadores que se articulam para o compartilhamento do cuidado.

Trazemos à baila uma reflexão de Raps que transcende a mera justaposição de serviços como parâmetro de análise, para colocar em questão o modo em que estão se relacionando, reconhecendo a existência e conformação de uma 'rede viva' que se estabelece no cotidiano dos serviços e dos indivíduos que por eles circulam $^{16}$. Rede viva, pois formada por serviços e pessoas em relações dinâmicas e dialógicas que se articulam em um processo complexo, individual e coletivo e que envolve setores e, principalmente, atores e seus saberes, símbolos, afetos e memórias.

Defendemos que, para que a rede instituída mediante leis e portarias ministeriais se concretize no território, é mister a construção cotidiana das relações em rede, seja com base no trabalho vivo em ato ${ }^{24}$, seja por meio de articulações entre os serviços de saúde, as equipes, os saberes (científicos, interdisciplinares e da tradição), as práticas e as subjetividades ${ }^{25}$.

Outro ponto evocado à luz do debate é a necessidade de considerar as características sociais, culturais, físicas e funcionais dos pontos que conectam a rede - os serviços - para o estabelecimento de arranjos e rearranjos que supram as necessidades sociais e de saúde dos usuários ${ }^{26}$.

Nesse sentido, consideramos que as redes não são simplesmente um arranjo poliárquico entre diferentes atores dotados de certa autonomia, mas um sistema que busca aprofundar e estabelecer padrões estáveis de inter-relações - estabilidade que admitimos ser relativa, pois 
em movimento, já que reconhecemos a própria complexidade da vida com suas idas e vindas, encontros e desencontros. A rede transcende o ajuntamento de serviços, ela requer a adoção de elementos que deem sentido a esse entrelaçamento de ações e processos ${ }^{27}$. Como um modelo complexo de promoção da saúde ${ }^{28}$, a rede equivale a estruturas sistêmicas abertas em constante mudança, totalidades compostas por partes inter-relacionadas, elementos mutantes, conexões e parâmetros.

De tal modo, admitimos a Raps como um todo complexo, que se concretiza no cotidiano dos serviços, em território, por meio de inter-relações concretas e intersubjetivas que sofrem influência do contexto histórico (tradição) e social desses indivíduos. Sendo constituída por nós - pontos de atenção distribuídos em território e responsáveis pela oferta de serviços $^{3}$ - e por ligações materiais e imateriais que os comunicam - as quais denominamos fios - que se materializam por meio dos fluxos assistenciais, das relações interpessoais e das linhas de cuidado.

Aceitamos o sistema de saúde como um sistema complexo com conexões e interconexões dentro e fora do setor saúde ${ }^{\mathbf{1 2}}$. Reconhecemos, também, a própria formação da rede de saúde como um fenômeno complexo, pois cada conexão possui características próprias, uma vez que envolve profissionais, e um corpo de saber, e usuários com características peculiares, em diferentes contextos e situações. Assim, a Raps está situada em um contexto multidimensional, com múltiplas conexões e inter-relações.

Arriscando uma leitura preliminar da Raps sob o olhar da complexidade, reconhecemos a objetividade das leis e portarias ministeriais, dos serviços e das normatizações que os conformam. Percebemos também a subjetividade inerente aos atores dessa rede e à interação entre eles, às emergências do cotidiano dos serviços e ao território em toda sua dinamicidade. Entre eles e junto com eles, conformando essa rede viva, reconhecemos ordem e desordem em constante interação.
É no diálogo e na complementaridade entre esses componentes que a rede se concretiza, auto-organiza-se e avança.

O princípio da dialogicidade se apresenta no contexto da Raps também no que concerne à coexistência entre modelos de atenção e serviços com diferentes inclinações assistenciais - cura, prevenção, reabilitação -, diversas especialidades, níveis e complexidades dentro da mesma rede temática. Além desses pontos, salientamos a relação dialógica que se estabelece entre o dentro/fora dos serviços de saúde. Relação esta que, na atualidade da atenção psicossocial, vem desencadeando tensões na rede, principalmente pela postura que os Caps vêm assumindo no contexto da atenção em rede territorial com pouca interlocução com outros elementos da rede e com a sociedade.

Acrescentamos que, enquanto rede viva, a Raps vibra 'ao som' ou não dos movimentos dos atores sociais que por ela circulam ao passo que esses mesmos atores têm seu caminhar orientado pelas políticas que institucionalizam a própria rede. Temos nessa sentença a expressão da recursividade que delineia os atores gestores, trabalhadores, usuários/familiares e a comunidade - como produtos e produtores da Raps; estando todos esses elementos influenciando e sendo influenciados por um emaranhado de contextos econômico, histórico, social e político. Tais indicativos nos fazem reconhecer a Raps como um sistema auto-eco-organizador que não pode bastar-se a si mesmo, concluir-se, fechar-se, ser autossuficiente ${ }^{10}$.

No contexto da Raps, essa dependência com o mundo exterior se apresenta com maior força ao considerarmos que a atualidade do cuidado em saúde mental suscita a saída do hospital psiquiátrico e a ocupação dos espaços da cidade. Nesse novo cenário, a vida em comunidade e a livre circulação pelo território, com as emergências cotidianas típicas deste convívio, são condições fundamentais. Assim, fechar-se em si mesma ou, dito de outro modo, negligenciar essa abertura à comunidade - ao social - vem causando tensões e contradições na própria rede. 
Em aproximação teórica às experiências brasileiras de cuidado em saúde mental em rede, o que se vê é o Caps como o cenário privilegiado para as investigações científicas, por vezes considerado como o 'lugar do louco' e o responsável pelo mandato social da loucura ${ }^{29-31}$. Evidenciamos que muito se fala sobre a necessidade e a dificuldade de articulação entre os serviços que compõem a Raps, porém pouco se problematiza sobre os modos de articulação, as potencialidades e as dificuldades de promovê-la, como também possíveis alternativas de transposição das barreiras encontradas. Percebe-se que a assistência à saúde mental, grosso modo, ainda não incorporou plenamente o discurso e a lógica da assistência em rede, as relações em rede são ainda incipientes e carecem de uma maior aproximação à matriz conceitual das RAS.

Sobre os modos de articulação da Raps, encontramos maior ênfase na inter-relação entre a APS e o Caps ${ }^{29,32,33}$. Em se tratando das potencialidades da rede, elencam-se: a construção/fortalecimento de uma rede solidária e cooperativa de saúde mental municipal e regional ${ }^{32}$; avanços no cuidado em saúde mental de base comunitária e na inserção da saúde mental na APS, com utilização de ligações telefônicas como estratégia de comunicação entre os profissionais ${ }^{34}$; trabalho coletivo e dialógico ${ }^{35}$; comunicação dentro da rede favorecida pelo uso de tecnologias leves, como a escuta e o vínculo e proporcionada pelo matriciamento ${ }^{33}$.

As dificuldades de articulação da Raps é tema recorrente nas publicações da área. Em síntese, os autores elencam como fatores associados a tal problemática: desarticulação entre os serviços substitutivos (atenção especializada) e AB seja por preconceito dos profissionais, seja por dificuldades de comunicação ou por desconhecimento sobre os fluxos assistenciais agravado pela incipiência dos esforços de aproximação entre os serviços ${ }^{26,29,35-40}$; pouca flexibilidade nos fluxos assistenciais, cristalizando a construção de trajetos assistenciais mais dinâmicos ${ }^{39}$; falta de sistematização para as trocas de informações sobre os usuários e para os encaminhamentos dentro da rede ${ }^{29,41}$; intervenções fragmentadas e pouco flexíveis ${ }^{38}$; dificuldades políticas, inclusive desinteresse pela saúde mental e precarização dos vínculos trabalhistas ${ }^{29,36}$.

De maneira geral, confirma-se a constatação de redes que privilegiam articulações funcionais entre os equipamentos que pouco se comunicam com os territórios em que vivem os usuários, em um modus operandi hegemônico que tem na rede o lugar de oferta técnica de cuidado, em uma tendência ao isolamento temático e à supervalorização dos serviços especializados ${ }^{\mathbf{4 2}}$.

Com base no exposto, sentimo-nos impelidos a um processo reflexivo que perpassa por dois pontos principais.

O primeiro deles refere-se à priorização do serviço de atenção psicossocial - o Caps - e de profissionais especializados - psiquiatras e psicólogos - quando a lógica organizacional da rede coloca a APS e a articulação entre esta e a atenção psicossocial como características fundamentais da atenção a este público específico, negligenciando-se, por vezes, a integralidade da atenção e o exercício da cidadania. Indício problemático, visto que, para dar conta da complexidade humana, o cuidado deve ser prestado à pessoa em sua totalidade ${ }^{\mathbf{4 3}}$. Reconhecemos que a busca pelos Caps é importante, considerando-se as demandas específicas dos sujeitos que caminham pela linha do cuidado em atenção psicossocial. O que colocamos em questão é quando a atenção desenvolvida nesses serviços assume um caráter não comunicante, ou seja, não busca a interação complementar entre os demais componentes da RAS/Raps, ficando a atenção restrita ao Caps ou, em outros casos, ao hospital psiquiátrico, que, apesar de não fazer parte da Raps, ainda apresenta representatividade considerável nas práticas de saúde mental e que, por este motivo, é considerado nesta discussão.

O segundo ponto remete aos modos de articulação fragilizados que, quando existentes, antepõem a relação APS-Caps, ficando 
os outros componentes da Raps à margem do processo. Sobre este segundo tópico, esclarecemos que não é a intenção minimizar a importância dos serviços especializados no contexto da Raps, mas, sim, elevar o nível e a complexidade do debate, abrindo possibilidades para outros focos de análise. Além de alertar para a posição lacunar que os serviços de urgência e emergência vêm ocupando na referida rede, com possíveis complicações para a continuidade do cuidado em território.

A impressão que se tem é que, ao se colocar sob os holofotes da ciência (e do senso comum?), a temática atenção psicossocial, uma linha abismal - no sentido propugnado por Boaventura de Souza Santos ${ }^{\mathbf{4}}$ - estabelece-se, separando 'deste lado da linha' os componentes específicos/temáticos da Raps e isolando 'do outro lado da linha' os demais componentes da rede. Nesse ponto de vista, e tomando como referência o contexto da atenção psicossocial em rede, parece existir uma linha imaginária que coloca os serviços especializados como 'o lugar' do cuidado, ficando à margem - por vezes esquecidos - do processo saúde-doença-cuidado os demais componentes da Raps, em que pese a relevância destes para a continuidade do cuidado em território.

Assim, a parte se separa do todo de maneira praticamente inatingível, a essência do cuidado em rede é pulverizada pelo domínio da especialidade e do saber-poder médico psiquiátrico, o que, a nosso ver, apresenta-se como um dos grandes paradoxos da Raps. Paradoxo, pois, assim como reconhecemos uma interdependência hologramática entre Raps-RAS, aceitamos a existência desse mesmo princípio entre os componentes temáticos (Caps, residências terapêuticas, entre outros) e os componentes transversais (APS, urgência e emergência, hospitais gerais) da rede em análise - já que, em tese, cada componente possui dentro de si a lógica organizacional da atenção em rede, além do que, é na inter-relação que se constituem enquanto RAS.

Alertamos para a negligência que se observa em relação à interdependência entre os serviços de saúde mental e os próprios recursos do meio ambiente/comunidade/sociedade, que se torna mais preocupante se considerarmos a imprescindibilidade desta relação (serviço-meio ambiente/comunidade/sociedade; dentro/fora) para o modelo de atenção psicossocial ao qual se afilia a Raps fato constatado pelo vazio teórico com o qual se depara ao se revisitar publicações da área ${ }^{31}$.

Pensando a Raps na perspectiva da complexidade, desafios são evocados à luz do debate. O primeiro deles é a distância entre a intenção - manifestada em Portarias Ministeriais $\mathrm{n}^{\mathrm{o}} 4.279 / 2010^{7}$ e $\mathrm{n}^{\mathrm{o}} 3.088 / 2011^{2}$ - e o gesto concreto de oferecer um atendimento integral, contínuo e efetivo aos usuários, inclusive com profissionais habituados a uma assistência focada nas partes e não no todo articulado e interdependente do sistema de saúde ${ }^{\mathbf{1 2}}$.

A esse respeito, há que se considerar nessa trama o compromisso dos trabalhadores da saúde mental com a concretização da rede e a continuidade do cuidado. Questionamo-nos, então, se a atmosfera de críticas e de luta dos trabalhadores que envolveu e nutriu o movimento de RPB foi obnubilada ao longo desses quase 40 anos? A nosso ver, em que pese as tensões e contradições da Raps e do trabalho em rede, é mister trazer trabalhadores, usuários e sociedade para discutir alternativas para transpor as barreiras que ora se apresentam ante a linha do cuidado em atenção psicossocial e investir na formação permanente dos técnicos, indivíduos que estão na ponta do sistema implementando (ou não) as políticas públicas de saúde.

O segundo ponto que se coloca em reflexão é a exigência de flexibilidade e olhar dinâmico por parte da gestão das RAS para que estas transcendam o mero emaranhado de fios com pontos incomunicáveis ${ }^{12}$. Sem a flexibilidade e a readaptação do sistema a partir das diversidades regionais tão caras à atenção em rede, vê-se cair por terra a rede plástica, horizontal e sensível às mudanças ${ }^{28}$.

Reconhecemos o avanço inegável da desinstitucionalização da assistência em saúde 
mental potencializado pela criação da Raps. Entretanto, consideramos a existência de realidades problemáticas no contexto da assistência à saúde mental em rede que perpassam, entre outros pontos, pela articulação entre os serviços que a compõem e pela emergência de fluxos assistenciais labirínticos. Nesse sentido, a saúde complexa e transdisciplinar - com interação e troca de saberes, numa dinâmica construtiva e criativa, de forma essencialmente transdisciplinar ${ }^{45}$ - parece ainda incipiente. As constatações deste ensaio nos colocam a impressão de que o cuidado em rede ainda é uma realidade distante, seja pela desmobilização de pessoas e grupos sociais para uma luta coletiva por melhores condições de vida e saúde ${ }^{45}$, seja pelo esmaecimento político-ideológico e sociocultural dentro do próprio movimento de RPB ${ }^{31}$.

Entretanto, a existência de esforços, ainda que pontuais e localizados, conferem fôlego às manobras de reestruturação da assistência à saúde mental em rede e nos impulsiona a transpor os muros que ora se apresentam à efetivação teórico-prática da atenção à saúde mental em rede.

\section{Considerações finais}

Ao longo deste ensaio reconhecemos que tensões se apresentam no âmbito do cuidado em saúde mental em rede territorial. Chamou-nos atenção o isolamento do componente temático da rede - principalmente os Caps -, o que, a nosso ver, reflete a persistência do domínio da especialidade médico-psiquiátrica em detrimento do cuidado e do trabalho em rede.

Sobre a tendência de os Caps fecharem-se em si próprios, no que cumpre em convidar e convocar os diversos pontos da rede a atuarem como atores da territorialização, ponderamos se o serviço especializado fecha-se em si mesmo ou se foi sitiado por velhas barreiras invisíveis que isolam a 'doença mental' nas paredes, agora, do Caps.
Colocamos em reflexão esse fechamento/ aprisionamento dos componentes temáticos da Raps enquanto uma contradição provocada pela atmosfera cultural na qual está inserido, com predomínio do poder médico-psiquiátrico como balizador das relações entre atores, serviços e setores. O que também pode ser potencializado pelo esmaecimento da militância que, nos anos dourados da RPB, conclamava uma 'sociedade sem manicômios até o ano 2000'.

Considerando o círculo recursivo de produção da atenção à saúde mental em rede, no qual o cuidado ao sujeito que sofre de transtorno mental influencia e é influenciado pelos modos de articulação da Raps, julgamos primordial garantir a integração e interlocução dos pontos de atenção das redes de saúde no território. Isso porque reconhecemos as implicações dessa articulação entre atores/serviços/setores para a integralidade e continuidade da assistência.

Assim, aceitar a relação dialógica que se estabelece entre os espaços dentro/fora dos serviços da Raps, assim como a hologramaticidade que se estabelece entre a Raps/RAS, e apostar na interdisciplinaridade e na intersetorialidade parece-nos uma alternativa para fazer fluir o cuidado e as relações em rede; dado que, quando se cuida de maneira integral, a intersetorialidade e a articulação para a continuidade do cuidado se tornam condição sine qua non à prática. Quando se reconhece a necessidade de compartilhamento do cuidado, aí está implícita a visão integral do sujeito e o reconhecimento da limitação do serviço, e até mesmo do setor saúde, em dar conta do sujeito e sua essência bio-psico-social-espiritual.

Reconhecendo, pois, a complexidade dos movimentos de intersetorialidade dentro e fora do setor saúde - muitos deles impulsionados pelas (inter)subjetividades dos diversos atores das RAS -, julgamos ser preciso transitar pelos micro e macro espaços das políticas de saúde, assistência e seguridade social e estimular uma cultura da intersetorialidade que transcenda o domínio teórico para atingir o campo prático de atuação profissional rumo a um 'agir intersetorial'. 


\section{Colaboradores}

Lima DKRR (0000-0003-0616-0286)* contribuiu para a concepção, o planejamento, a análise, a interpretação dos dados, além da elaboração do rascunho do conteúdo. Guimarães J (0000-0003-4664-5886)* contribuiu com discussões conceituais sobre a temática e para a aprovação da versão final do manuscrito.

\section{Referências}

1. Amarante P. A (clínica) e a Reforma Psiquiátrica. In: Amarante P, organizador. Archivos de Saúde Mental e Atenção Psicossocial. Rio de Janeiro: NAU Editora; 2003. p. 45-65.

2. Brasil. Ministério da Saúde, Gabinete do Ministro. Portaria no 3.088, de 23 de dezembro de 2011. Institui a Rede de Atenção Psicossocial para pessoas com sofrimento ou transtorno mental e com necessidades decorrentes do uso de crack, álcool e outras drogas, no âmbito do Sistema Único de Saúde (SUS). Diário Oficial da União. 30 Jun 2011.

3. Mendes EV. As Redes de Atenção à Saúde. 2. ed. Brasília, DF: Organização Pan-Americana de Saúde; 2011.

4. Lobosque AM. Debatendo alguns desafios da Reforma Psiquiátrica brasileira. Ciênc. Saúde Colet. 2011; 16(12):4590-4602.

5. Carvalho AL, Amarante P. Avaliação de qualidade dos novos serviços de saúde mental: em busca de novos parâmetros. Saúde debate [internet]. 1996 [acesso 2019 fev 2]; 52:74-82. Disponível em: http://docvirt.com/ asp/acervo_cebes.asp?Bib=SAUDEDEBATE\&PASTA=N.52+-+ set. $+1996 \&$ pesq $=\& x=55 \& y=12$.

${ }^{*}$ Orcid (Open Researcher and Contributor ID). forma complexa de agir. Vigil. sanit. debate. 2013; 1(1):12-20

7. Brasil. Ministério da Saúde, Gabinete do Ministro. Portaria $n^{0} 4.279$, de 30 de dezembro de 2010. Estabelece diretrizes para a organização da Rede de Atenção à Saúde no âmbito do Sistema Único de Saúde (SUS). Diário Oficial da União. 31 Dez 2010.

8. Brasil. Ministério da Saúde. Comissão Intergestores Tripartite. Resolução $\mathrm{n}^{\circ}$ 32, de 14 de dezembro de 2017. Estabelece as Diretrizes para o Fortalecimento da Rede de Atenção Psicossocial (RAPS). Diário Oficial da União. 22 Dez 2017.

9. Brasil. Ministério da Saúde. Portaria no 3.588 , de 21 de dezembro de 2017. Altera as Portarias de Consolidação no 3 e n ${ }^{0}$ 6, de 28 de setembro de 2017, para dispor sobre a Rede de Atenção Psicossocial, e dá outras providências. Diário Oficial da União. 22 Dez 2017.

10. Morin E. Introdução ao pensamento complexo. 5. ed. Porto Alegre: Sulina; 2015.

11. Amarante P. Saúde Mental e Atenção Psicossocial. 2. ed. Rio de Janeiro: Fiocruz; 2007 
12. Arruda C, Lopes SGR, Koerich MHAL, et al. Redes de atenção à saúde sob a luz da teoria da complexidade. Esc. Anna Nery Rev. Enferm. 2015; 19(1):169173.

13. Minayo MCS. O desafio do conhecimento: pesquisa qualitativa em saúde. 14. ed. São Paulo: Hucitec; 2014.

14. Bedin DM, Scarparo HBK. Integralidade e saúde mental no SUS à luz da teoria da complexidade de Edgar Morin. Psicol. teor. prát. 2011; 13(2):195-208.

15. Morin E. Ciência com consciência. 15. ed. rev. Rio de Janeiro: Bertrand Brasil; 2013.

16. Brasil. Ministério da saúde, Secretaria de Atenção à Saúde. Política Nacional de Humanização da Atenção e Gestão do SUS. Redes de Produção de Saúde. Brasília, DF: MS, 2009.

17. Oliveira NRC. Redes de atenção à saúde: a atenção à saúde organizada em redes. São Luís: UNA-SUS/ UFMA; 2015.

18. Mendes EV. As redes de atenção à saúde. Ciênc. Saúde Colet. 2010; 15(5):2297-2305.

19. Amarante P. Loucos pela vida: a trajetória da reforma psiquiátrica no Brasil. 2. ed. Rio de Janeiro: Fiocruz; 1995.

20. Yasui S. Rupturas e encontros: desafios da Reforma Psiquiátrica brasileira. Rio de Janeiro: Fiocruz; 2010.

21. Franco CM, Franco TB. Linhas do cuidado integral: uma proposta de organização da rede de saúde. [internet]. [acesso 2018 jul 5]. Disponível em: http:// www.saude.sp.gov.br/resources/humanizacao/homepage/acesso-rapido/formacao-tecnica-em-acolhimento-na-atencao-basica/passo_a_passo_linha de_cuidado.pdf.

22. Organização Pan-Americana da Saúde. Atenção à saúde coordenada pela Atenção Primária à Saúde: construindo as redes de atenção no SUS: contribuições para o debate. Brasília, DF: Opas; 2011.
23. Brasil. Ministério da Saúde, Secretaria de Atenção à Saúde, Departamento de Ações Programáticas Estratégicas. Saúde Mental em Dados 12. Ano 10. Brasília, DF: MS, 2015 .

24. Quinderé PHD, Jorge MSB, Franco TB. Rede de Atenção Psicossocial: qual o lugar da saúde mental? Physis. 2014; 24(1):253-271.

25. Franco TB. As redes na micropolítica do processo de trabalho em saúde. In: Pinheiro R, Mattos RA, organizadores. Gestão em Redes: práticas de avaliação, formação e participação na saúde. Rio de Janeiro: Cepesc; 2006. p. 459-474.

26. Antonacci MH, Kantorski LP, Willrich JQ, et al. Estrutura e fluxo da rede de saúde como possibilidade de mudança nos serviços de atenção psicossocial. Rev. Esc. Enferm. USP. 2013; 47(4):891-898.

27. Santos L, Andrade LOM. Redes no SUS: marco legal. In: Silva SF, organizador. Redes de Atenção à Saúde: desafios da regionalização no SUS. 2. ed. rev. Campinas: Saberes; 2013. p. 13-23.

28. Almeida-Filho N. A Saúde e o Paradigma da Complexidade. Cad. Inst. Humanitas Unisinos; 2006; 4(15):145 .

29. Miranda L, Oliveira TFK, Santos CBT. Estudo de uma Rede de Atenção Psicossocial: paradoxos e efeitos da precariedade. Psicol. ciênc. prof. 2014; 34(3):592-611.

30. Delgado PG. Limites para a inovação e pesquisa na reforma psiquiátrica. Physis. 2015; 25(1):13-18.

31. Ramos DKR, Paiva IKS, Guimarães J. Pesquisa qualitativa no contexto da Reforma Psiquiátrica brasileira: vozes, lugares, saberes/fazeres. Ciênc. Saúde Colet. 2019; 24(3):839-852.

32. Almeida AB, Aciole GG. Gestão em rede e apoio institucional: caminhos na tessitura de redes em saúde mental no cenário regional do Sistema Único de Saúde (SUS). Interface (Botucatu). 2014; 18(supl1):971981. 
33. Sousa FSP, Jorge MSB, Vasconcelos MGF, et al. Tecendo a rede assistencial em saúde mental com a ferramenta matricial. Physis. 2011; 21(4):1579-1599.

34. Silva GM. A articulação da saúde mental em Redes de Atenção à Saúde: a perspectiva dos trabalhadores da Estratégia de Saúde da Família e do Centro de Atenção Psicossocial de Santa Cruz do Sul-RS [dissertação]. Porto Alegre: Universidade Federal do Rio Grande do Sul; 2013. 93 p.

35. Ballarin MLGS, Carvalho FB, Ferigato SH, et al. Centro de atenção psicossocial: convergência entre saúde mental e coletiva. Psicol. estud. 2011; 16(4):603-611.

36. Silva NS. Panorama dos serviços de saúde mental no interior do estado de Goiás. [dissertação]. Goiânia: Universidade Federal do Goiás; 2012. 230p.

37. Onocko-Campos R, Baccari IP. A intersubjetividade no cuidado à Saúde Mental: narrativas de técnicos e auxiliares de enfermagem de um Centro de Atenção Psicossocial. Ciênc. Saúde Colet. 2011; 16(4):20512058.

38. Severo AK, Dimenstein M. Rede e intersetorialidade na atenção psicossocial: contextualizando o papel do ambulatório de saúde mental. Psicol. ciênc. prof. 2011; 31(3):640-655.

39. Teixeira-Jr S. Trajetórias assistenciais de usuários com transtornos psíquicos na rede de saúde no município de Porto Alegre. [dissertação]. Porto Alegre: Universidade Federal do Rio Grande do Sul; 2010. $131 \mathrm{p}$.

40. Azevêdo MS. O cuidado à saúde mental em rede em um distrito sanitário de Salvador, BA: discussões e desafios para a integração de serviços. [dissertação]. Salvador: Universidade Federal da Bahia; 2010. 156 p.

41. Viega LP. A rede de serviços de atenção psicossocial na região sudeste da cidade de São Paulo: potencialidades e limites. [dissertação]. São Paulo: Pontifícia Universidade Católica de São Paulo; 2012. 125 p.

42. Souza TP, Carvalho SR. Apoio territorial e equipe multirreferencial: cartografias do encontro entre o apoio institucional e a redução de danos nas ruas e redes de Campinas, SP, Brasil. Interface (Botucatu). 2014; 18(supl1):945-56.

43. Demarco DA, Jardim VMR, Kantorski LP. Cuidado em saúde às pessoas com transtorno mental na rede de atenção psicossocial. Cuidado é fundamental [internet]. 2016 [acesso 2019 fev 4]; 8(3):4821-4825. Disponível em: http://www.seer.unirio.br/index.php/ cuidadofundamental/article/view/4361/pdf_1

44. Santos BS. Más allá del pensamiento abismal: de las líneas globales a una ecología de saberes. In: Olivé L, Santos BS, Salazar C, et al, organizadores. Pluralismo epistemológico. La Paz: Muela del Diablo Editores; Comuna; Consejo Latinoamericano de Ciencias Sociales; CIDES - UMSA; 2009. p. 31-84.

45. Spagnuolo RS, Guerrini IA. A construção de um modelo de saúde complexo e transdisciplinar. Interface (Botucatu). 2005; 9(16):191-194.

Recebido em 07/02/2019

Aprovado em 29/07/2019

Conflito de interesses: inexistente

Suporte financeiro: não houve 